\title{
Projecting US Primary Care Physician Workforce Needs: 2010-2025
}

\author{
Stephen M. Petterson, $\mathrm{PbD}^{1}$ \\ Winston R. Liaw, MD, MPH \\ Robert L. Pbillips, Jr, MD, MSPH \\ David L. Rabin, MD, MPH \\ David S. Meyers, $M D^{4}$ \\ Andrew W. Bazemore, MD, MPH \\ 'The Robert Graham Center, Policy \\ Studies in Family Medicine and Primary \\ Care, Washington, DC \\ ${ }^{2}$ Virginia Commonwealth University, \\ Department of Family Medicine, \\ Richmond, Virginia \\ ${ }^{3}$ Georgetown University, Department \\ of Family Medicine, Washington, DC \\ ${ }^{4}$ Agency for Healthcare Research and \\ Quality, Washington, DC
}

Conflicts of interest: authors report none.

\section{CORRESPONDING AUTHOR}

Winston Liaw, MD, MPH 3650 Joseph Siewick Dr, \#400 Fairfax, VA 22033

winstonrliaw@gmail.com

\begin{abstract}
PURPOSE We sought to project the number of primary care physicians required to meet US health care utilization needs through 2025 after passage of the Affordable Care Act.

METHODS In this projection of workforce needs, we used the Medical Expenditure Panel Survey to calculate the use of office-based primary care in 2008. We used US Census Bureau projections to account for demographic changes and the American Medical Association's Masterfile to calculate the number of primary care physicians and determine the number of visits per physician. The main outcomes were the projected number of primary care visits through 2025 and the number of primary care physicians needed to conduct those visits.
\end{abstract}

RESULTS Driven by population growth and aging, the total number of office visits to primary care physicians is projected to increase from 462 million in 2008 to 565 million in 2025. After incorporating insurance expansion, the United States will require nearly 52,000 additional primary care physicians by 2025 . Population growth will be the largest driver, accounting for 33,000 additional physicians, while 10,000 additional physicians will be needed to accommodate population aging. Insurance expansion will require more than 8,000 additional physicians, a $3 \%$ increase in the current workforce.

CONCLUSIONS Population growth will be the greatest driver of expected increases in primary care utilization. Aging and insurance expansion will also contribute to utilization, but to a smaller extent.

Ann Fam Med 2012;10:503-509. doi:10.1370/afm.1431.

\section{INTRODUCTION}

W ith passage of the Affordable Care Act (ACA), health insurance coverage will expand to an additional 34 million people in the United States. ${ }^{1}$ After Massachusetts mandated health insurance in 2006, primary care wait times increased, even though the state has the second highest ratio of primary care physicians to population of any state and a robust network of community health centers ${ }^{2,3}$ Reports statewide of physicians with limited capacity to see additional patients prompted Dr Mario Motta, President of the Massachusetts Medical Society, to declare that universal coverage does not equal universal access. ${ }^{4}$ Insurance expansion is expected to have a greater impact nationally, as the use of services by the nation's 46.3 million uninsured is likely to rise. ${ }^{5}$ President Obama has recognized this challenge and called for an immediate and long-term expansion of the nation's primary care physicians, nurse practitioners, and physician assistants. Our aim is to explain the potential size of this growth.

Prior research has consistently demonstrated the association between having insurance and increased health services use. The Association of American Medical Colleges (AAMC) projected that universal coverage will increase use of all physicians by $4 \%,{ }^{6}$ while the Bureau of Health Professions projected a $5.2 \%$ increase. $^{7}$ Our analysis uses population-based nationally representative utilization data to project the number of primary 
care physicians needed to address expected increases in use due to insurance expansion. These data can be combined with supply projections to determine whether a shortage will persist.

Our analysis differs from previous projections in the following ways. First, we focused on primary care services. Second, in determining need, we incorporated recommendations from recent studies to adjust our primary care physician workforce estimates to account for physicians either not seeing patients or not providing primary care. Further, we used a nationally representative health utilization data set, not previously used for these types of studies, but that allowed us to more accurately estimate projected primary care use. Finally, we adjusted our projections to account for the estimated impact of insurance expansion made possible through the ACA. As a result, we come to a somewhat different conclusion about future needs and how to meet them.

Researchers have disagreed about the existence of a physician shortage. In 2008, the AAMC projected a shortage of 124,000 full-time equivalent physicians by 2025 with primary care accounting for the largest share $\left(37 \%\right.$ or 46,000 full-time equivalents). ${ }^{6}$ Similarly, an analysis by Colwill et $\mathrm{al}^{8}$ projected that increased workloads combined with a declining supply would create a shortage of 44,000 generalists by 2025 . Both argued that an expanding and aging population would consume more resources..$^{9,10}$ Others contend that current primary care scarcities are due to geographic maldistribution, which may not improve even if the supply increases without specific policies regarding training, recruitment, and retention. ${ }^{11,12}$ Regardless, as insurance expands, use of primary care physicians will change, raising concerns about the adequacy of the current workforce.

\section{METHODS}

\section{Overview}

To calculate future primary care physician workforce needs, we began by estimating current primary care utilization rates and the size of the current US primary care physician workforce. These figures were used to estimate the average number of annual visits a physician conducts. Next, using Census data and current primary care utilization, we projected the number of annual primary care visits Americans will make based on population growth and aging. Finally, using the differences in current primary care utilization rates between those with and without insurance, we estimated increases in primary care utilization as a result of the ACA's insurance expansion. On the basis of the expected number of annual primary care office visits and our estimate of the number of visits a primary care physician conducts in a year, we calculated the future primary care physician workforce needs.

\section{Current Annual Primary Care Physician Office Visits}

To determine the number of primary care office visits, we used the 2008 Medical Expenditure Panel Survey (MEPS), which is administered by the Agency for Healthcare Research and Quality and collects data from a nationally representative sample of individuals and families regarding health conditions, health status, use of medical services, insurance coverage, and access to care. MEPS queries a sample of the civilian, noninstitutionalized population regardless of their health care use, thereby allowing estimates of mean office visits by age, sex, and insurance status. Using data from MEPS, we calculated the mean number of primary care physician office visits per person, defined as visits to a general practitioner, family physician, pediatrician, geriatrician, or general internist. On the basis of our analysis (described subsequently), we estimated that $46.4 \%$ of all physician office visits are to primary care physicians. This figure is slightly lower than but comparable to data from the 2007 National Ambulatory Medical Care Survey (NAMCS) showing that $50 \%$ of all physician office visits are to primary care physicians. ${ }^{13}$

\section{Number of Primary Care Physicians}

We identified primary care physicians in the 2010 American Medical Association (AMA) Masterfile by selecting physicians in direct patient care with a primary, self-designated specialty of family medicine, general practice, general internal medicine, general pediatrics, or geriatrics. To address the fact that the AMA Masterfile undercounts retirees, ${ }_{1}^{14}$ we adjusted the figures after comparing the age distribution of physicians in the AMA Masterfile with the subset of these physicians who could be matched in the National Provider Identifier database. We then decreased general internist counts by $20 \%$ to account for hospitalists and those in non-primary care settings ${ }^{15}$ and decreased counts for family physicians, pediatricians, and geriatricians by $5 \%$ to account for those working primarily in urgent or emergency care.*

Our 2010 figures may undercount physicians as we excluded the nearly 10,000 physicians with unspecified specialties and 20,000 physicians with unknown patient care status. Others have voiced concern that the Masterfile does not adequately capture physicians who have

* This figure is based on an analysis of American Board of Family Medicine data showing that roughly $5 \%$ to $6 \%$ of family physicians report spending more than $50 \%$ of their time in urgent or emergency care (Petterson $\mathrm{S}$ et al, oral communication, Oct 13, 2010). 
left direct patient care, however. Without more reliable data, we assumed that these issues are offsetting.

\section{Number of Visits per Primary Care Physician}

We divided the total estimated annual number of physician office visits by the estimated number of practicing physicians to determine the current annual visits per primary care physician in the United States.

\section{Projected Primary Care Physician Office Visits}

We calculated the mean number of office-based visits to primary care physician for each age category and sex, using MEPS from 2008 for the insured and uninsured populations. To determine the impact of population expansion and aging, we applied these rates to the US Census Bureau projected populations for 20102025 for population groups by age category and sex to calculate the total office-based visits for the entire projected population.

\section{Projected Need for Primary Care Physicians}

To estimate the number of primary care physicians needed to accommodate the projected number of office visits given population expansion and aging, we divided the total number of projected visits by the current number of annual visits per physician.

To estimate increased primary care physician use after the ACA goes into effect, we first calculated the number of physicians needed with universal coverage. To calculate the total office-based visits for a universally insured population, we multiplied the mean number of office-based visits (using MEPS data for insured patients only) by the entire projected US population (for each age and sex category) and substituted this figure into the aforementioned equations to calculate the number of physicians needed under universal coverage. The marginal primary care physician need was estimated by removing the physicians needed as a result of population aging and growth.

This marginal need was then multiplied by the proportion of the currently uninsured who are likely to receive coverage under ACA to account for those who will remain uninsured despite the ACA, calculated as the ratio of the Centers for Medicare and Medicaid Services (CMS) yearly estimate of the increased percentage of insured under the ACA and the percentage of uninsured in the absence of ACA.* These projections do not account for the likely geographic maldistribution of additional primary care physicians. They are also conservative in that certain segments of the uninsured (such as older individuals) may be sicker than the insured and could use more services if insured. ${ }^{16}$

* CMS provides yearly estimates of the impact of ACA on insurance expansion starting from 2010.

\section{RESULTS \\ Current Annual Primary Care Physician Office Visits}

In 2008, according to MEPS, Americans made 977 million office visits to physicians, 462 million of which were to primary care physicians. These figures are similar to those available from NAMCS, which show 994 million visits to physician's office and 50\% of those-497 million—to primary care physicians. For the civilian, noninstitutionalized population, this value represents a mean of 1.60 primary care physician visits per person yearly. On average, women made more office visits than men, and older adults made more than younger ones (Figure 1). The insured made more visits than the uninsured with the gap widening as people age. Men were more likely to be uninsured than women, with men aged 18 to 24 years being the most likely to be uninsured.

\section{Number of Primary Care Physicians}

The AMA Masterfile indicates that there were 246,090 primary care physicians in direct patient care in 2010 (Table 1). After adjusting for retirement or those practicing as hospitalists, in emergency departments, and in urgent care centers, 208,807 primary care physicians provided office-based primary care in that year. In a parallel analysis of the 2008 AMA Masterfile, we estimated that there were 243,360 primary care physicians in direct patient care. Using the same proportion of unadjusted to adjusted counts as in 2010 $(208,807 / 246,060=84.8 \%)$, we estimated an adjusted count of $206,369(243,360 \times 84.8 \%)$ in 2008 .

\section{Number of Visits per Primary Care Physician}

In 2008, assuming 462 million total office visits to primary care physicians and 206,369 such physicians, we estimated 2,237 visits per primary care physician yearly. The United States had 1 practicing primary care physician for every 1,475 persons, not accounting for variations in distribution.

\section{Projected Primary Care Physician Office Visits}

According to Census projections, the population will increase by $15.2 \%$ from 2010 to $2025 .{ }^{9}$ Although all segments are expected to increase, the population aged older than 65 years will grow by $60 \%$, while those aged younger than 18 years will increase by $13 \%$. The population thus will both increase overall and age. Using these projections and the mean office visits for each age and sex category calculated for our base year of 2008, we project that the total number of office visits to primary care physicians for the United States will increase from a base of 462 million in 2008 to 565 million in 2025. Because of aging, the average number of visits to 
Figure 1. Number of office-based visits in 2008 by age, sex, and insurance status, and percentage of patients uninsured.

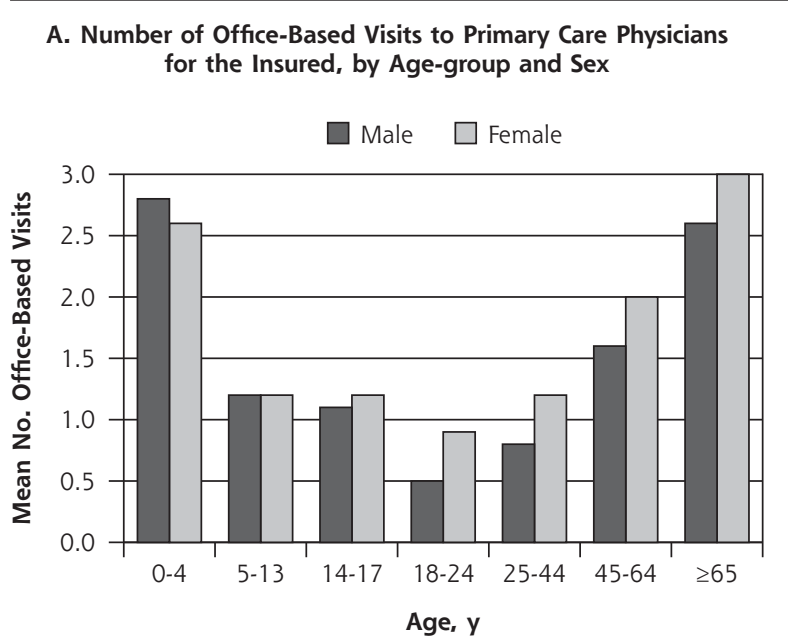

B. Number of Office-Based Visits to Primary Care Physicians for the Uninsured, by Age-group and Sex

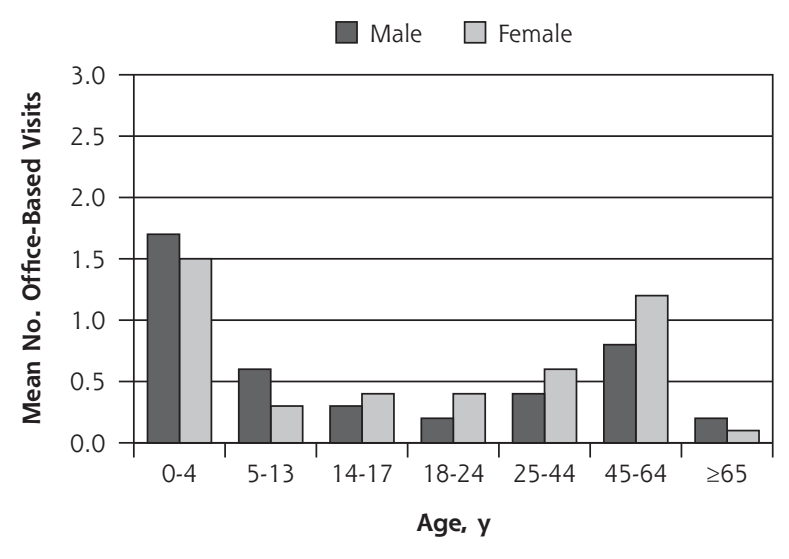

C. Difference in Annual Office-Based Visits to Primary Care Physicians Between Insured and Uninsured, by Age-group and Sex

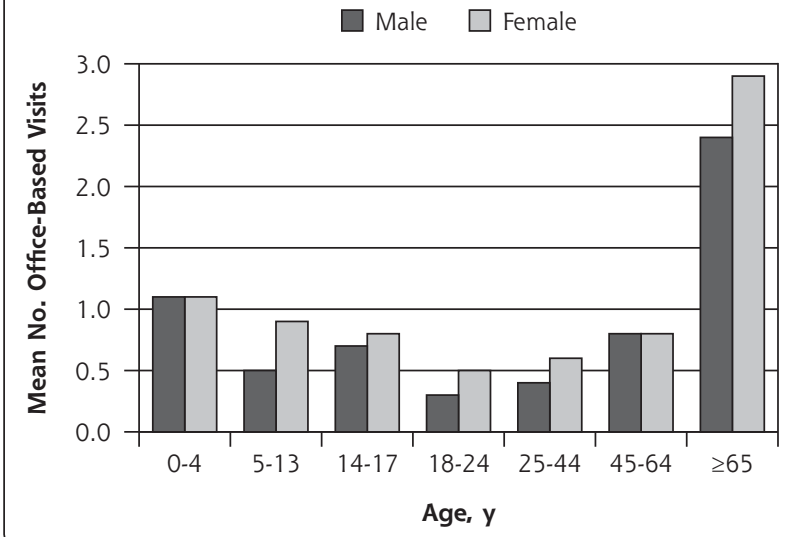

D. Percentage Uninsured, by Age-group and Sex

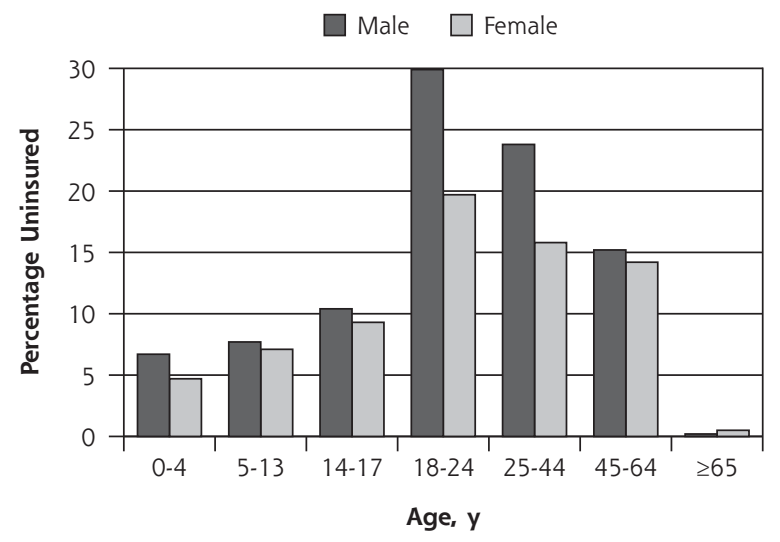

Table 1. Numbers of Primary Care Physicians in Direct Patient Care, 2010

\begin{tabular}{lccc}
\hline & & $\begin{array}{c}\text { Adjusted by Excluding } \\
\text { Physicians Who: }\end{array}$ \\
\cline { 3 - 4 } Specialty & Unadjusted & Are Retired & $\begin{array}{c}\text { Do Not Practice } \\
\text { Primary Care }\end{array}$ \\
\hline Family medicine & 87,650 & 84,033 & 79,831 \\
Geriatrics & 3,260 & 3,157 & 2,999 \\
General practice & 11,883 & 9,557 & 9,557 \\
General internal medicine & 93,655 & 89,359 & 71,487 \\
General pediatrics & 49,642 & 47,297 & 44,933 \\
Total & 246,090 & 233,403 & 208,807 \\
\hline a American Medical Association Masterfile 2010. & & \\
b Physician counts were decreased by $3 \%$ for those aged 55 to 59 years, $8.7 \%$ for those aged 60 \\
to 64 years, $20.1 \%$ for those aged 65 to 69 years, $26.2 \%$ for those aged 70 to 74 years, $38.4 \%$ for \\
those aged 75 to 79 years, $54.3 \%$ for those aged 80 to 84 years, $70.6 \%$ for those aged 85 to 89 \\
years, $81.4 \%$ for those aged 90 to 98 years, and $100 \%$ for those aged 99 years and older. \\
\hline
\end{tabular}

primary care physicians increases from 1.60 in 2008 to 1.66 in 2025.

\section{Projected Need for Primary Care Physicians}

Assuming the average primary care physician sees 2,237 visits yearly, to meet the increased need for primary care office visits, additional physicians will be required. By 2025 the United States would require nearly 260,687 practicing primary care physicians, an increase of 51,880 from the current workforce (Table 2). Most of this increased need is attributable to gradual population growth and aging (Figure 2). In contrast, the increase from insurance expansion 


\section{Table 2. Projected Primary Care Physician Need Under Various Conditions by Year}

\begin{tabular}{lcrrr}
\hline Condition & $\mathbf{2 0 1 0}$ & $\mathbf{2 0 1 5}$ & $\mathbf{2 0 2 0}$ & \multicolumn{1}{c}{$\mathbf{2 0 2 5}$} \\
\hline Baseline & 209,662 & 209,662 & 209,662 & 209,662 \\
Aging of population & - & 2,693 & 6,264 & 9,894 \\
Population growth & - & 11,201 & 21,952 & 32,852 \\
ACA coverage & - & 7,104 & 8,097 & 8,279 \\
Total & 209,662 & 230,660 & 245,975 & 260,687 \\
\hline ACA = Affordable Care Act. & & & & \\
\hline
\end{tabular}

In 2011, Hofer and colleagues ${ }^{17}$ projected utilization after insurance expansion and demonstrated that insurance expansion will result in 15 to 24 million additional primary care visits. Using similar sources and methods, we estimate an additional 19.5 million visits. Hofer et a $1^{17}$ concluded that these visits will require an additional 4,300 to 6,900 primary care physicians, whereas we estimate 8,000 primary care physicians are needed. This discrepancy may be explained by differences in assumptions regarding productivity. They project how many physicians would be needed if all were full time, estimating that a full-time, wellestablished family physician sees 3,500 visits yearly. Our estimate incorporates a lower productivity figure based on the number of office visits yearly the current primary care physician workforce conducts. This lower figure encompasses the realities of medical practice where competing demands-administration, teaching, research, hospital work, and part-time practice-result in many physicians not conducting office visits full time. We therefore approximate that 8,000 primary

Figure 2. Growing need for primary care physicians, 2010-2025.

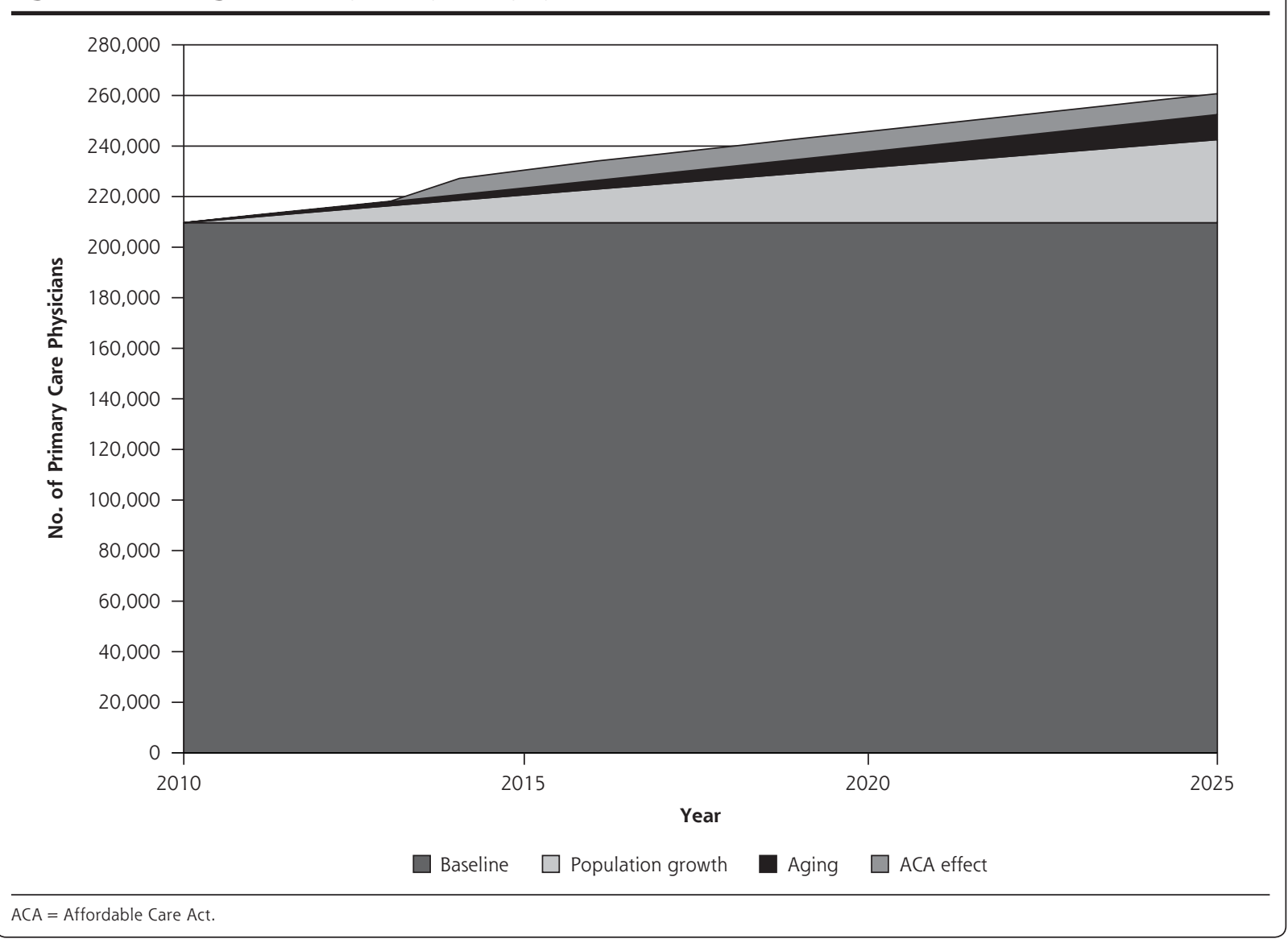


care physicians will need to enter the workforce to do the work of 6,000 full-time equivalent office-based primary care physicians.

The ACA included several measures to support the primary care workforce. In 2010, the Health Resources and Services Administration distributed \$168 million to expand the number of medical school graduates entering primary care residencies and $\$ 75$ million to increase training for physician assistants and nurse practitioners. This one-time investment is expected to produce 500 additional physicians, so even if these positions were maintained for 10 years, only 5,000 additional primary care physicians would be trained. Sustained funding for primary care training was also proposed in the President's 2011 budget. In addition, the ACA revitalized the workforce development infrastructure by establishing a National Health Care Workforce Commission and directed an $\$ 11$ billion investment to community health centers over the next 5 years. ${ }^{18,19}$

A rich source of additional primary care physicians exists in the current internal medicine pipeline. The number of internal medicine residents choosing primary care has decreased with most subspecializing. ${ }^{20}$ Increasing the number of internal medicine residents pursuing primary care would increase primary care physicians at no additional cost. The ACA included provisions to increase the attractiveness of primary care. Proposed increases for primary care physician reimbursement from Medicare and Medicaid, emphasis on patient-centered medical homes, and outlines for a national primary care extension service, if funded and implemented, would help support a satisfied and productive primary care physician workforce.

In addition to increasing the primary care physician supply, policy makers must also consider distribution issues. Our estimates do not account for the uneven distribution of services whereby some areas experience pervasive shortages. The newly insured will only exacerbate this maldistribution if they cluster in physician-scarce areas. Policy options that increase the size of the primary care workforce without addressing distribution will be less successful. More funding for programs such as the National Health Service Corps has the potential to reverse this inequity.

\section{Limitations}

It is critical to recognize that there are many limitations inherent in these projections. We used MEPS, which did not allow for calculation of visits to physician assistants or nurse practitioners. Regarding productivity, we adjusted neither for differences between specialties ${ }^{21}$ nor for decreases in productivity over time. ${ }^{22}$ In projecting workforce needs, we held constant 2008 utilization rates. This projection thus does not reflect poten- tial changes in primary care-such as increases in efficiency from information technology, non-visit-based models, or moves toward patient-centered medical home models. Furthermore, we did not account for the effect of high-deductible health plans, although they may decrease utilization. ${ }^{23}$ We assumed that current use projects future use, and did not attempt to address optimal utilization. We did not project pent-up demand and commensurate higher utilization that may occur as formerly uninsured individuals become insured. Finally, we could not determine the percentage of time in direct patient care and therefore could not account for non-office-based activities. This possibly accounts for the low number of visits yearly per physician.

\section{Next Steps}

Projecting use under various scenarios informs a larger assessment of workforce demand and supply. Further analysis is needed regarding the supply of primary care physicians adjusting for physicians entering and leaving primary care. Research and guidance regarding the appropriate response of graduate medical education will be critical to ensuring that the workforce can meet the projected increases in utilization. More research is required on the association between workforce ratios and outcomes, such as the ratio of primary care physicians per population that would minimize costs and improve quality. It will also be important to understand where the uninsured are located and where access is limited.

Population growth will be the greatest driver of increased primary care utilization, requiring approximately 33,000 additional primary care physicians by 2025. Aging will also contribute to needs, but to a smaller extent, while insurance expansion will require 8,000 additional primary care physicians. In areas with an adequate primary care physician workforce, the projected increase in utilization may be met by increases in productivity. Given current maldistribution, however, we cannot expect increased demand to be met by increased productivity universally. Capacity building thus requires both immediate and long-term attention to deliver on the ACA's promise of better, more affordable, and more accessible care.

To read or post commentaries in response to this article, see it online at http://www.annfammed.org/content/10/6/503.

Key words: health policy research; primary care issues; insurance; Affordable Care Act; workforce; physician shortage

Submitted February 10, 2012; submitted, revised, May 31, 2012; accepted June 19, 2012.

Funding support: This research was funded in part by the Agency for Healthcare Research and Quality through contract number HHSP233200900359P, reference number AHR1256. 
Disclaimer: The statements and opinions expressed in this article are those of the authors and do not represent the official position of the Department of Health and Human Services or the Agency for Healthcare Research and Quality. The information and opinions contained in research from the Graham Center do not necessarily reflect the views or policy of the American Academy of Family Physicians.

Acknowledgments: We would like to acknowledge Barbara Culliton for her assistance in editing the manuscript.

\section{References}

1. Foster RS. Estimated financial effects of the "Patient Protection and Affordable Care Act," as amended. Centers for Medicare $\varepsilon$ Medicaid Services; 2010. https://www.cms.gov/ActuarialStudies/ Downloads/PPACA_2010-04-22.pdf. Accessed Mar 26, 2011.

2. The Kaiser Family Foundation. Nonfederal primary care physicians per 1000 population, 2008. American Medical Association, Physicians Professional Data. Kaiser Family Foundation; 2008. http:// statehealthfacts.org/profile.jsp. Accessed Feb 7, 2010.

3. National Association of Community Health Centers. Key health center data by state, 2007, based on 2007 Uniform Data System. Bureau of Primary Health Care, HRSA, HHS; 2008. http:// www.nachc.org/client/documents/state_X_key_facts_2007v3.pdf. Accessed Feb 10, 2010

4. Gulla R. MMS physician workforce study finds continued shortages in primary care. Massachusetts Medical Society News Releases; June 26, 2009. http://www.massmed.org/AM/Template. cfm?Section=MMS_News_ReleasesECONTENTID = 31507ETEMPL $\mathrm{ATE}=/ \mathrm{CM} /$ ContentDisplay.cfm. Accessed Feb 22, 2010

5. DeNavas-Walt C, Proctor BD, Smith JC. Income, Poverty, and Health Insurance Coverage in the United States: 2006. Washington, DC: US Census Bureau; 2007. http://www.census.gov/prod/2007pubs/p60233.pdf. Accessed Feb 22, 2010.

6. Dill MJ, Salsberg ES. The Complexities of Physician Supply and Demand: Projections Through 2025. Association of American Medical Colleges; 2008. http://www.innovationlabs.com/pa_future/1/ background_docs/AAMC\%20Complexities\%20of\%20physician\%20 demand,\%202008.pdf. Accessed Feb 7, 2010.

7. Health Resources and Services Administration. Physician Supply and Demand: Projections to 2020. Department of Health and Human Services; 2006. http://www.achi.net/HCR\%20 Docs/2011HCRWorkforceResources/Physician\%20Supply\%20 and\%20Demand-2020\%20kl.pdf. Accessed Feb 22, 2010.

8. Colwill JM, Cultice JM, Kruse RL. Will generalist physician supply meet demands of an increasing and aging population? Health Aff (Millwood). 2008;27(3):w232-w241.

9. Bureau of the Census. Table 2: Projections of the population by selected age groups and sex for the United States: 2010 to 2050 (NP2008-T2). In: Population Division, US Census Bureau. Washington, DC: Population Division, US Census Bureau; 2008
10. Institute of Medicine. Retooling for an Aging America. Washington, DC: The National Academies Press; 2008.

11. Council on Graduate Medical Education. 10th Report. Physician Distribution and Health Care Challenges in Rural and Inner-city Areas. Washington, DC: US Department of Health and Human Services, Health Resources and Services Administration; 1998.

12. Green LA, Dodoo MS, Ruddy G, et al. The Physician Workforce of the United States: A Family Medicine Perspective. Washington, DC: The Robert Graham Center; 2004. http://www.graham-center.org/ PreBuilt/physician_workforce.pdf. Accessed Feb 22, 2010.

13. National Center for Health Statistics. Health, United States, 2009: With Special Feature on Medical Technology. Hyattsville, MD: National Center for Health Statistics; 2010.

14. Staiger DO, Auerbach DI, Buerhaus PI. Comparison of physician workforce estimates and supply projections. JAMA. 2009;302(15): 1674-1680.

15. Kuo YF, Sharma G, Freeman JL, Goodwin JS. Growth in the care of older patients by hospitalists in the United States. N Engl J Med. 2009;360(11):1102-1112

16. McWilliams JM, Meara E, Zaslavsky AM, Ayanian JZ. Use of health services by previously uninsured Medicare beneficiaries. $N$ Engl J Med. 2007;357(2):143-153.

17. Hofer AN, Abraham JM, Moscovice I. Expansion of coverage under the Patient Protection and Affordable Care Act and primary care utilization. Milbank Q. 2011;89(1):69-89.

18. National Association of Community Health Centers. Community health centers and health care reform: summary of key health center provisions, 2010. http://www.nachc.com/client/Summary\%20of\%20 Final\%20Health\%20Reform\%20Package.pdf. Accessed Apr 5, 2010.

19. National Association of Community Health Centers, Inc. A Sketch of Community Health Centers: Chart Book 2006. Figures 1.1 and 3.1. Bethesda, MD: National Association of Community Health Centers, Inc; 2006. http://www.nachc.com/client/documents/research/Chart_ Book__2006.pdf. Accessed Apr 5, 2010.

20. Jeffe DB, Whelan AJ, Andriole DA. Primary care specialty choices of United States medical graduates, 1997-2006. Acad Med. 2010; 85(6):947-958.

21. National Center for Health Statistics. Health, United States, 2008: With Special Feature on the Health of Young Adults. Hyattsville, MD: National Center for Health Statistics; 2009. http://www.cdc.gov/ nchs/data/hus/hus08.pdf\#095. Accessed Feb 12, 2010.

22. Staiger DO, Auerbach DI, Buerhaus PI. Trends in the work hours of physicians in the United States. JAMA. 2010;303(8):747-753.

23. Wharam JF, Landon BE, Galbraith AA, Kleinman KP, Soumerai SB, Ross-Degnan D. Emergency department use and subsequent hospitalizations among members of a high-deductible health plan. JAMA. 2007;297(10):1093-1102. 